\title{
DIFICULDADES APRESENTADAS POR ALUNOS SURDOS NA AQUISIÇÃO DE CONCEITOS QUÍMICOS
}

\author{
DIFFICULTIES SHOWN BY DEAF STUDENTS IN THE ACQUISITION OF \\ CHEMICAL CONCEPTS
}

Raul Freitas Lima*

\section{Resumo}

Este artigo traz algumas reflexões sobre as dificuldades apresentadas por alunos surdos na aquisição de conceitos químicos. Entende-se que as dificuldades desses estudantes são as mesmas dos alunos ouvintes, em decorrência da baixa carga horária da disciplina, da elevada abstração dos conceitos e da ausência de laboratórios. Entretanto, algumas características dos alunos surdos, somadas às dificuldades anteriores, dificultam ainda mais sua aprendizagem. Entre esses fatores estão: a ausência de formação científica do Intérprete da Língua de Sinais, a inexistência de sinais para determinados conceitos científicos e a língua portuguesa, utilizada pelo professor, diferente da língua do aluno surdo.

Palavras-chave: Ensino de química. Estudantes surdos. Educação inclusiva.

A apropriação de conceitos científicos pelos estudantes nos anos finais do ensino fundamental e durante todo o ensino médio é importante para a formação da cidadania assim como para o desenvolvimento da capacidade de tomada de decisão (SANTOS; SCHNETZLER, 1996). Segundo os Parâmetros Curriculares Nacionais do Ensino Médio (PCNEM), a Lei de Diretrizes e Bases da Educação Nacional (LDB) e o Plano Nacional de Educação (PNE) são conhecimentos que possibilitarão a formação de cidadãos críticos, autônomos e reflexivos.

De acordo com o PCN+ Ensino Médio, que contém orientações complementares aos Parâmetros Curriculares Nacionais, abordando as Ciências da Natureza, a Matemática e as suas Tecnologias, o conhecimento químico formulou-se, historicamente, centrado em "estudos de natureza empírica sobre as transformações químicas e as propriedades dos materiais e

\footnotetext{
* Licenciado em Química pela Universidade de São Paulo (USP), Ribeirão Preto, São Paulo, Brasil. E-mail: raulfreitaslima2013@gmail.com
} 
substâncias" (BRASIL, 2002, p 87). Observa-se ainda, nessa publicação, que os modelos explicativos se desenvolveram gradualmente "conforme a concepção de cada época, e atualmente, o conhecimento científico em geral e o da Química em particular requerem o uso constante de modelos extremamente elaborados" (BRASIL, 2002, p 87).

Em conformidade com a história de seu próprio desenvolvimento como ciência, a Química deve ser apresentada, como consta no PCN+ Ensino Médio, estruturada sobre três pilares: (1) as transformações químicas, (2) os materiais e suas propriedades e (3) os modelos explicativos. $\mathrm{O}$ documento afirma ainda que a tríade anterior sustenta de forma harmoniosa o conhecimento de química do estudante (BRASIL, 2002).

Segundo o art. 35 da LDB 9.394/96, o ensino médio tem como função a "compreensão dos fundamentos científico-tecnológicos dos processos produtivos, relacionando a teoria com a prática, no ensino de cada disciplina” (BRASIL, 2002, p 87). Além disso, o educando terá que demonstrar ao término do ensino médio "domínio dos princípios científicos e tecnológicos que presidem a produção moderna" (BRASIL, 1996). O aprendizado de Química pelos alunos, de acordo com o PCNEM implica que:

[...] eles compreendam as transformações químicas que ocorrem no mundo físico de forma abrangente e integrada e assim possam julgar com fundamentos as informações advindas da tradição cultural, da mídia e da própria escola e tomar decisões autonomamente, enquanto indivíduos e cidadão (BRASIL, 2000, p. 31).

No que diz respeito ao Ensino Fundamental ( $5^{\circ}$ ao $8^{\circ}$ ano), o mesmo PCNEM determina que:

[...] não se pode perder de vista que a aprendizagem científica, no ensino fundamental, é principalmente o reconhecimento do mundo e uma primeira construção de explicações. Pautada nas explicações científicas, a aprendizagem avança, passando a constituir novas formas de pensamento do estudante (BRASIL, 1998, p. 88).

Este artigo traz algumas reflexões acerca das dificuldades apresentadas por alunos ouvintes e surdos na aquisição de conceitos químicos, abordando, especificamente, o processo de apropriação dos conceitos químicos pelos alunos surdos. A princípio é possível perceber que não se trata de um problema exclusivo dos alunos surdos, uma vez que alunos ouvintes também apresentam problemas para a assimilação dos mesmos conceitos. 
A partir dos documentos citados anteriormente, fica evidente que a elaboração de explicações, a construção de novas formas de pensar e a tomada de decisões de forma autônoma são essenciais na formação do aluno, seja ele surdo ou não. Se o alto nível de abstração dos conceitos científicos é um problema comum para os estudantes de ciências, o processo de ensino-aprendizagem para o aluno surdo pode ser ainda mais comprometido, caso o Intérprete da Língua de Sinais (ILS) não tenha formação científica; se o professor fala uma língua (português) diferente da língua do aluno (Libras); e ainda, se não há sinais correspondentes em Libras que descrevam de forma adequada os conceitos químicos.

A apropriação de conhecimentos científicos pelos alunos surdos é muito importante para sua formação pois, segundo Nascimento, Fernandes e Mendonça (2010, p. 237), esse conhecimento: "promove um questionamento de seus saberes cotidianos, podendo possibilitarlhes uma intervenção criativa e crítica na realidade na qual se inserem, tendo em vista sua compreensão e possível transformação".

Neste artigo optou-se por dar ênfase maior à problemática que envolve linguagem e abstração dos conceitos. Essa escolha se dá em parte devido aos poucos trabalhos existentes no Brasil sobre o ensino de química para surdos (Sousa; Silveira, 2008). Antes de abordarmos a aquisição dos conceitos químicos, porém, é importante lembrar que a exclusão da população surda não é processo recente. De acordo com Merselian e Vitaliano (2009, p. 3737) "os surdos durante os diversos períodos da história foram colocados à margem do mundo econômico, social, cultural, educacional e [...] considerados como deficientes, incapazes e desapropriados de seus direitos e da possibilidade de escolhas".

Se a população surda foi historicamente excluída dos espaços escolares, como esperar que se apropriem de conhecimentos imprescindíveis para a sua vida? Tal como preconizam os documentos oficiais, esses conhecimentos são importantes para a sua formação, pois possibilitam sua inserção no mundo do trabalho e na prática social.

As dificuldades apresentadas pelo estudante surdo ao longo do processo de aprendizagem podem ser analisadas sobre dois pontos de vista: a dos alunos e a dos professores. Segundo os alunos, o professor tem pouca influência nas dificuldades de aprendizagem, mas quando elas surgem, listam como principais causas: a instrumentação, a lógica e a linguagem da disciplina (SILVA et al., 2010). De acordo com Mendonça e Cruz (2008, p. 1) duas circunstâncias diferentes são entraves para o processo de ensino-aprendizagem de Química: “falta de um laboratório para a realização de aulas práticas e o conteúdo da disciplina ser muito 
abstrato, não existindo ligação com a realidade do dia-a-dia”. No entanto, uma das principais dificuldades apresentadas pelos alunos para sua aprendizagem é a linguagem química. Essa linguagem é observada pelos Parâmetros Curriculares Nacionais para o Ensino Médio (PCNEM):

Deve-se considerar que a Química utiliza uma linguagem própria para a representação do real e as transformações químicas, através de símbolos, fórmulas, convenções e código. Assim, é necessário que o aluno desenvolva competências adequadas para reconhecer e saber utilizar tal linguagem, sendo capaz de entender e empregar, a partir das informações, a representação simbólica das transformações químicas (BRASIL, 2000, p.34).

Para Pereira e Benite (2011, p. 51) "a linguagem química é uma integração sinérgica de palavras, gráficos, diagramas, figuras, equações e tabelas, dentre outras formas de expressão do conhecimento". Assim sendo, quando alunos apontam a linguagem química como obstáculo, podem estar se referindo aos códigos, símbolos, fórmulas, convenções e gráficos, o que de certa forma demanda tempo e dedicação para assimilá-los.

No entanto, se entendermos linguagem como "o elemento que estabelece a relação entre os seres humanos e propicia a experiência da intersecção ou interação entre interlocutores" (FILHO; TORGA. 2011, p. 3), é possível que uma linguagem como a química (dotada de símbolos, convenções e gráficos) limite a interação, ou intersecção, entre professores e alunos, surdos ou não. O segundo problema em destaque neste artigo é a elevada abstração dos conceitos químicos. Quadros et al. (2011, p.163) definem a Química como:

[...] uma ciência que trabalha situações do mundo real e concreto cujas explicações, na maioria das vezes, usam entidades do mundo chamado microscópico, tais como íons, elétrons, entre outros. Navegar nesse mundo infinitamente pequeno e, portanto, abstrato, usando a abstração para explicar o mundo real, é difícil para uma parte significativa dos estudantes.

Portanto, a Química pode ser compreendida como uma ciência que transita entre o universo microscópico e macroscópico. Para fazer essa transição, é importante que o aluno conheça bem esses dois níveis de representação e que faça abstrações.

Mais uma vez, temos um elemento que é próprio da Química e que pode dificultar a aprendizagem tanto de alunos surdos como de alunos ouvintes: a elevada abstração dos conceitos. Quadros et al. (2011, p. 167) amplia a lista de dificuldades, apontando: "ausência de 
laboratório, a baixa carga horária da disciplina, o excesso de alunos por turma e carga horária excessiva do professor (ou número elevado de turmas)".

Esses elementos se apresentam como agentes dificultadores tanto para alunos surdos como para ouvintes. Entretanto quando o aluno surdo adentra uma classe composta por alunos ouvintes, poderá se deparar com adversidades que poderão dificultar ainda mais a sua aprendizagem. A maior dificuldade no ensino das ciências em geral para os alunos surdos é, segundo Oliveira e Benite (2015, p. 470), a "barreira linguística”, pois:

[...] mesmo que o surdo tenha domínio da LIBRAS, que deveria ser sua primeira língua, o ensino de ciências é intermediado pelo ILS, que faz uma compreensão do que o professor está ensinando e repassa ao aluno surdo. Então, é preciso também que o ILS compreenda os termos utilizados pelo professor de ciências, ou seja, tenha o mínimo de conhecimento específico sobre o conhecimento que está a interpretar/traduzir, a fim de que a mensagem seja a mais fidedigna possível.

Não basta, portanto, que o aluno tenha domínio da LIBRAS. É necessário que o intérprete tenha noção dos conhecimentos básicos específicos, para que possa fazer a tradução e a interpretação do que é transmitido pelo professor da disciplina. A falta de sinais em Libras, correspondentes para conceitos Químicos, foi apontada por Barbosa e Pacheco (2014, p. 10) como um entrave à apropriação do conhecimento pelo surdo:

O maior problema observado foi a falta de sinais correspondentes em LIBRAS, para os termos técnicos em Química o que dificulta o processo de aprendizagem. Dessa forma, no ensino de Química, o discente surdo recebe as informações distorcidas e aprende o conteúdo de forma errônea, sendo muito prejudicado no processo de ensino aprendizagem.

Sousa e Silveira (2011, p. 40) alegam ainda que a falta de sinais traz prejuízo na negociação dos sentidos dos conceitos químicos entre intérpretes e surdos:

A química por exemplo, por trabalhar com conceitos em nível teórico (atômico-molecular) e ainda se utilizando de uma simbologia específica e representacional (fórmulas, equações, modelos), na explicação dos fenômenos químicos, possui o agravante do processo ensino-aprendizado ser dificultado pela falta de saberes necessários aos docentes que pudessem auxiliar a negociação de sentidos dos conceitos químicos entre intérpretes e surdos para, posteriormente, nessa negociação, haver a criação de sinais que reflitam a conceituação trabalhada. 
Sobre a linguagem química também é importante observar que:

[...] a especificidade da linguagem e dos termos químicos - átomo, elétron, mol, íon, próton, dentre outros - que não compõem o rol de terminologias dos dicionários de libras, pode ser um elemento dificultador da construção de sentidos dos conceitos químicos e, consequentemente, sua tradução do português para libras (SOUSA; SILVEIRA, 2011, p. 38).

Muitos conceitos — como os que representam átomos, substâncias químicas ou o mol por exemplo — são caros à Química e sua especificidade não permite a falta de conhecimentos do intérprete, considerando-se que essa omissão poderá prejudicar a posterior negociação de sentidos com o aluno surdo. A criação de novos sinais, é importante lembrar, não pode ser feita apenas pelo intérprete ou pelo professor da área específica, pois o aluno surdo deve participar dessa elaboração (MARQUES; SILVEIRA. 2010, p.1).

Vale ressaltar que o uso do laboratório de Química é imprescindível para que o processo de ensino-aprendizagem se efetive. As atividades experimentais facilitam o entendimento e a aquisição de conceitos científicos, despertando o interesse pela ciência de forma geral (BARBOSA; PACHECO, 2014). Quadros et al (2011, p. 163), ao avaliarem os currículos, observaram que:

[...] o conteúdo químico ensinado nas instituições de educação básica continua, muitas vezes, sendo "puro", ou seja, o conhecimento científico não é percebido pelo estudante como inserido em seu mundo de vida. Essas dificuldades institucionais para criar alternativas curriculares são utilizadas para reforçar a ideia (presentes em alguns órgãos oficiais) de que os professores são responsáveis por grande parte da não implementação de inovações que visam à melhoria na qualidade de ensino, porque colocam seus interesses pessoais acima das necessidades dos alunos.

Quando o aluno diz não ver relação dos conteúdos das disciplinas de Química com a sua realidade, refere-se ao conhecimento químico "puro", muitas vezes ensinado de forma descontextualizada. Não bastasse isso, o impedimento de alternativas curriculares concorre para que o professor seja visto como responsável pela não implementação de inovações que facilitariam a aprendizagem, especialmente dos alunos surdos, que têm aguçada percepção visuoespacial, e necessitam de exemplos e experiências práticas para compreenderem conceitos teóricos. 


\title{
Conclusão
}

A Química é uma ciência que apresenta linguagem própria e conceitos dotados de elevada abstração. Somadas à falta de laboratórios e carga horária reduzida da disciplina essas características apresentam-se como entraves para a aprendizagem de alunos sendo eles surdos ou não. Para a população de alunos surdos é importante lembrar que a falta da formação científica do intérprete, as divergências entre as línguas faladas pelo professor e pelo aluno, assim como a inexistência de sinais para determinados conceitos científicos, são elementos que podem comprometer ainda mais a aprendizagem dos surdos.

Sabemos que a cultura surda apresenta a singularidade de ser visual e que essa característica é muito significativa (BENITE, PEREIRA, 2011, p. 48). Sendo assim, o uso de recursos visuais, no decorrer das aulas, torna-se imprescindível. Sobre esses recursos, Gibin e Ferreira (2012, p. 25) observam que:

[..] o uso de imagens que apresentam os diferentes níveis de representação do conhecimento químico pode auxiliar no estabelecimento de relações entre a teoria e a prática no processo de imaginar os fenômenos químicos. É importante ressaltar a importância do emprego de imagens que representam o nível submicroscópico, que evidenciam as espécies químicas que não são observáveis e, por isso, auxiliam no processo de compreensão de um fenômeno químico.

Os recursos visuais são efetivos tanto para alunos surdos como para ouvintes. No entanto, quando as turmas forem inclusivas, com a presença de alunos surdos, o uso de ilustrações deve ser feito de forma mais intensa, por parte dos professores. Como uma das marcas da cultura surda é ser visuoespacial, a presença recorrente de imagens assim como a realização de experimentos em laboratórios (que possibilitam acompanhar operações descritas por equações químicas) irá promover uma aprendizagem mais significativa.

\begin{abstract}
This article brings some reflections on the difficulties presented by deaf students in the acquisition of chemical concepts. It is understood that the difficulties of these students are the same as those of hearing students, due to the low workload of the discipline, the high abstraction of concepts, and the absence of laboratories. However, some characteristics of deaf students, added to the previous difficulties, make their learning even more difficult. Among these factors are: the lack of scientific training of the Sign Language Interpreter, the absence of signs for
\end{abstract}


certain scientific concepts, and the Portuguese language used by the teacher, different from the language of the deaf student.

Keywords: Chemistry teaching. Deaf students. Inclusive education.

\section{Referências}

BARBOSA, K. C. M.; PACHECO, D. Química e surdez: novas propostas no processo de ensino. In: SIMPÓSIO NACIONAL DE ENSINO DE CIÊNCIAS E TECNOLOGIA, 4., 2014. Anais. Paraná.

BRASIL. Ministério de Educação e Cultura. LDB - Lei nº 9394/96, de 20 de dezembro de 1996. Estabelece as diretrizes e bases da Educação Nacional. Brasília: MEC, 1996.

Secretaria de Educação Fundamental. Parâmetros Curriculares Nacionais. Ciências Naturais. Brasília. MEC, 1998. 138 p.

Parâmetros Curriculares Nacionais. Ensino Médio. Brasília. MEC, 2000.

PCN+ Ensino Médio. Orientações educacionais complementares aos Parâmetros Curriculares Nacionais - Ciências da Natureza, Matemática e suas Tecnologias. Brasília: MEC. Semtec, 2002.

FILHO, U. C.; TORGA, V. L. M. Língua, discurso, texto, dialogismo e sujeito: compreendendo os gêneros discursivos na concepção dialógica, sócio-histórica e ideológica da língua. In: CONGRESSO NACIONAL DE ESTUDOS LINGUÍSTICOS, 1., 2011. Anais. Espírito Santo.

GIBIN, G. B.; FERREIRA, L. H. Avaliação dos estudantes sobre o uso de imagens como recurso auxiliar no ensino de conceitos químicos. Química Nova na Escola, São Paulo, v. 33, n. 1 , p. $19-26$, fev. 2012.

MARQUES, R. H.; SILVEIRA, H. E. Sinais de Libras sobre terminologias químicas. In: ENCONTRO NACIONAL DE ENSINO DE QUÍMICA, 15., 2010. Anais. Brasília: UnB, 2010.

MENDONÇA, M. L. T. G.; CRUZ, R. P. As dificuldades na aprendizagem da disciplina de química pela visão dos alunos do ensino médio. In: REUNIÃO ANUAL DA SOCIEDADE BRASILEIRA DE QUÍMICA, 31., 2008. Anais. São Paulo.

MERSELIAN, K. T.; VITALIANO, C. R. Análise sobre a trajetória histórica da educação dos surdos. In: Congresso Nacional de Educação, 9., 2009, Anais. Paraná.

NASCIMENTO, F.; FERNANDES, H. L.; MENDONÇA, V. M. O ensino de ciências no Brasil: história, formação de professores e desafios atuais. Revista HISTEDBR, Campinas, $\mathrm{n}$. 39 , p. $225-249$, set. 2010. 
OLIVEIRA, W. D.; BENITE, A. M. C. Aulas de ciências para surdos: estudos sobre a produção do discurso de interpretes de LIBRAS e professores de ciências. Ciênc. Educ., Bauru, v. 21, n. 2, p. $457-472,2015$

PEREIRA, L. L. S.; BENITE, C. M.; BENITE, A, M. C. Aula de Química e surdez: sobre interações pedagógicas mediadas pela visão. Química Nova na Escola, São Paulo, v. 33, n. 1, p. $47-56$, fev. 2011.

QUADROS, A. L. et al. Ensinar e Aprender Química: a percepção dos professores do Ensino Médio. Educar em Revista. Curitiba, Brasil, n. 40, p. 159 - 176, abr/jun. 2011. Editora UFPR.

SANTOS, W. L. P.; SCHNETZLER, R. P. O que significa ensino de química para formar o cidadão? Química Nova na Escola, São Paulo, v. 4, p. 28 - 34, nov. 1996.

SILVA, M. R. A. et al. As dificuldades apresentadas no aprendizado de Química apontadas por alunos da primeira série do Ensino Médio de Itajubá (sul de MG). In: ENCONTRO NACIONAL DE ENSINO DE QUÍMICA, 15., 2010. Anais. Brasília: UnB, 2010.

SOUSA, S. F.; SILVEIRA, H. E. O ensino de química para surdos como possibilidade de aprendizagens mútuas. In: ENCONTRO NACIONAL DE QUÍMICA, 14., 2008. Anais. Curitiba: UFPR, 2008.

Terminologias químicas em libras: a utilização de sinais na aprendizagem de alunos surdos. Química Nova na Escola, São Paulo, v. 33, n. 1, p. 37 - 46, fev. 2011. 